\title{
Correspondence
}

\section{Comparative risks of amniocentesis and fetal blood sampling}

Sir,

We read with interest the paper by Youroukos et al. ${ }^{1}$ on porencephalic cysts after amniocentesis. The report adds a central nervous system malformation to the literature regarding injury to the fetus after second trimester amniocentesis for prenatal diagnosis. The authors state that fetal trauma after second trimester amniocentesis is rare, and that the risk of such complications does not outweigh the value of the procedure in the prenatal diagnosis of $\beta$-thalassaemia.

In fact, the prenatal procedure used was not amniocentesis (removal of amniotic fluid), but fetal blood sampling. Midtrimester amniocentesis for antenatal detection of chromosomal and some genetic and congenital defects in at-risk populations is an accepted medical procedure. The risk of damage is low (about 0.5 to $1 \%$ at experienced centres). ${ }^{2}$

Fetal blood sampling however, is currently considered to be at an applied research state, and carries a much higher risk for the fetus (about $9.4 \%$ at experienced centres). ${ }^{3}$

It is important that the two techniques should remain separate when assessing the risks of fetal injury. Families who might benefit by amniocentesis might well deny themselves testing because of incorrect information.

\section{References}

1 Youroukos S, Papadelis F, Matsaniotis N. Porencephalic cysts after amniocentesis. Arch Dis Child 1980; 55: 814-5.

2 Kaback M D, ed. Predictors of hereditary disease or congenital defects. In: Antenatal diagnosis. National Institutes of Health Publication No 79-1973. Washington DC: US Government Printing Office, 1979: 1-263.

3 Alter B P, Orkin S H, Forget B G, Nathan D G. Prenatal diagnosis of hemoglobinopathies. The New England approach. Ann NY Acad Sci 1980; 344: 151-64.

Lorraine Suslak and Franklin Desposito Division of Human Genetics, and Department of Pediatrics, College of Medicine and Dentistry, New Jersey Medical School, Newark, New Jersey 07103, USA

\section{Porencephalic cysts as a result of placental damage at amniocentesis? \\ Sir,}

Youroukos et al. ${ }^{1}$ reported on an infant with porencephalic cysts after midtrimester amniocentesis for exclusion of $\beta$-thalassaemia. Obviously, the placenta was punctured without fetoscopy and fetal blood was obtained. There were no problems in obtaining fetal blood nor were there other apparent complications of the procedure. The authors considered brain damage through the amniocentesis needle the most likely origin of the porencephalic cysts, especially as 2 subcutaneous nodules were overlying the defect.

I should like to suggest another mode of origin for the cysts. The puncture of the placenta, on which occasion 'several specimens of fetal blood were obtained', probably resulted in placental damage. Embolisation of clots of necrotic tissue or of thrombotic material via the umbilical vein might have led to occlusion of a fetal cerebral artery. Consequent brain necrosis could have resulted in a porencephalic cyst. Such events have often been observed in monovular twin gestations after the death of one twin with a common placenta with vascular anastomoses. ${ }^{2}$ a The most common defects were porencephalic cysts, microcephaly, or hydrocephaly; however, skin lesions similar to the nodules in the patient of Youroukos et al., have been observed too. A Japanese group ${ }^{8}$ has recently shown by combined angiography and computerised tomography scan that a cerebral artery ended abruptly at the location of a cyst. Hence vascular occlusion was the most likely cause of the cyst.

In the case reported by Youroukos et al. ${ }^{1}$ several observations leave both possibilities open or might even favour a placentogenic origin of the cysts. Firstly the fact that the fetus (which would have been severely damaged by the needle) was not spontaneously aborted, secondly the uneventful puncture, and thirdly the discrepancy between severe brain damage and discrete 'needle points'.

In this particular case neither direct nor indirect damage of the fetus could be demonstrated; however, when using invasive prenatal measures the possibility of indirect damage of the fetus from embolic events caused by placental damage through a needle puncture should be considered.

\section{References}

1 Youroukos S, Papadelis F, Matsaniotis N. Porencephalic cysts after amniocentesis. Arch Dis Child 1980; 55: 814-5.

2 Schinzel A A G L, Smith D W, Miller J R. Monozygotic twinning and structural defects. J Pediatr 1979; 95: 921-30.

3 Yoshioka H, Kadomoto Y, Mino M, et al. Multicystic encephalomalacia in liveborn twin with a stillborn macerated co-twin. J Pediatr 1979; 95: 798-800.

A SCHINZEL

Institute of Medical Genetics, University of Zürich,

Steinwiesstrasse 75, CH-8032 Zürich,

Swit zerland

\section{Metoclopramide poisoning in children}

Sir,

I read with great interest the paper by Low and Goel ${ }^{1}$ and should like to comment on two points: 
(1) In their discussion they stated, 'although it has been reported (by Casteels-Van Daele et al.) that children can have these side effects with the dose recommended by the manufacturers their patients received a dose varying between 0.56 and $1.15 \mathrm{mg} / \mathrm{kg}$ per day'. This statement was made in 1970 when we first reported on dystonic reactions caused by metoclopramide and I want to stress that at that time that was right. ${ }^{2}$ Indeed, then manufacturers recommended a dose of 0.5 to $1 \mathrm{mg} / \mathrm{kg}$ per day, but later they lowered it to $0.5 \mathrm{mg} / \mathrm{kg}$ per day. However, even on this dose dystonic reactions can occur as shown by Cases 7 and 9 in our later series of patients who received a dose of 0.52 and $0.48 \mathrm{mg} / \mathrm{kg}$ per day. ${ }^{3} \mathrm{We}$ therefore have to accept that a normal dose of metoclopramide can induce acute dystonic reactions. The patient should be warned in order to avoid unexplained and distressing situations later.

(2) It is right that 'such reactions can be effectively stopped by administration of benztropine $1 \mathrm{mg}$ intravenously'. We too have used benztropine with spectacular results, all symptoms stopping almost immediately, but one of our patients developed an atropine-like intoxication characterised by a psychotic state with extreme agitation, loquaciousness, hallucinations, motor restlessness, and bradycardia, starting 3 hours after intravenous injection and lasting for $\mathbf{1 7}$ hours. Children seem to be sensitive to atropine-derivatives and we suggest that $1 \mathrm{mg}$ intravenously (irrespective of age) may be too high a dose. In the younger ones ( 1 to 5 years old) a dose of $0.5 \mathrm{mg}$ seems to be safer. In our experience a small dose can be given by slowly injecting intravenously and stopping as soon as the dystonic reactions disappear. If the dystonic reactions are not too severe, by far the safest therapy is to stop the administration of metoclopramide immediately.

\section{References}

1 Low L C K, Goel K M. Metoclopramide poisoning in children. Arch Dis Child 1980; 55: 310-2.

2 Casteels-Van Daele M, Jaeken J, Van der Schueren P, Zimmerman A, Van den Bon P. Dystonic reactions in children caused by metoclopramide. Arch Dis Child 1970; 45: $130-3$.

3 Casteels-Van Daele M, Jaeken J. Metoclopramide (Primperan) and its side-effects. Tijdschr Gastroenterol 1971 ; 14: 205-15.

Maria Casteels-Van Daele Academisch Ziekenhuis Gasthuisberg, B-3000 Leuven, Herestraat 49, Belgium

\section{Visceral larva migrans and Trichuris vulpis}

Sir,

Sakano et al. ${ }^{1}$ reported 2 cases of visceral larva migrans (VLM) which they concluded were due to infection with Trichuris vulpis. They based this conclusion on the results of immunoelectrophoretic studies in which precipitation lines were found between the patients' serum and $T$. vulpis antigen. Precipitation was also found against
Toxocara canis but it was concluded that this was nonspecific according to results of immunoelectrophoresis. ${ }^{2}$ Treatment with thiabendazole was considered effective on the basis of a decrease in the number of arcs of precipitate and in the eosinophil count.

We are reluctant to accept $T$. vulpis as the cause of the VLM in these cases for the following reasons:

(1) There is no evidence that $T$. vulpis (a common parasite of the caecum and large-intestine of dogs) follows more than a transient migration, as an immature worm, into the glands of the gut wall of its usual host before emerging into the gut lumen as an adult.

(2) Immunological methods of diagnosis for helminth infections are not generally precise, even with so-called 'purified' specific antigens, and can seldom give more than an indication of relationship to a nematode and not true identity.

(3) Even if the results were to prove that the patients had an antibody response specific for $T$. vulpis, this would not be evidence of visceral migration. Dogs infected by the parasite show a rise and fall in antibody titres in response to local invasion of the bowel and there is no reason to believe this would not happen in man. The immunology of $T$. vulpis has been reviewed by Beer. ${ }^{3}$

(4) Thiabendazole is not a particularly effective antihelmintic for treatment of adult $T$. vulpis in dogs. In VLM due to $T$. canis symptoms subside spontaneously, including the eosinophilia (though generally after the clinical symptoms), irrespective of treatment. We feel that in these cases the response ascribed to thiabendazole was likely to be coincidental.

(5) We think that the positive precipitation reaction to $T$. canis antigen (admittedly non-specific) is a more likely cause of the symptoms described, particularly since Toxocara sp. is a known cause of VLM.

We agree that the diagnosis of VLM can be difficult and final proof can be established only be demonstrating the larvae in the tissues. Nevertheless, we are unhappy to add yet another parasite as a cause of this syndrome without clearer evidence.

\section{References}

1 Sakano T, Hamamoto K, Kobayashi Y, Sakata Y, Tsuji M, Usui $T$. Visceral larva migrans caused by Trichuris vulpis. Arch Dis Child 1980; 55: 631-3.

2 Tsuji M. Comparative studies on the antigenic structure of several helminths by immunoelectrophoresis. Jpn $J$ Parasitol 1975; 24: 227-36.

8 Beer R J. Whipworms of domestic animals. Vet Bull 1971; 41 : 343-9.

J B S COULTER Department of Tropical Paediatrics,

J M JeWSBURY Department of Parasitology,

W N BEEsLey Veterinary Parasitology,

WENDY BaILEY Department of Tropical Medicine, Liverpool School of Tropical Medicine, Pembroke Place, Liverpool L3.5QA 